an integrated programme in human biology and ecology at Yale University based on the joint contributions which Yale College and the School of Medicine might make. The Fund has also provided 96,500 dollars towards a study of the state of the resources of the University of Florida which can, and should, be woven into the pattern of medical education.

In the field of Experimental Health Services the Fund has been most interested in integrating health care, and its main grant has been a further 158,100 dollars in support of the large experiment in integrated health care at the Hunterden Medical Centre, New Jersey, which a sound and ably led rural community is building, with a further 250,000 dollars to meet the emergency arising from the sharp increase in building costs. In effect, the plan adds a general staff to existing health services of the United States, and also seeks to encourage a keener understanding of people in need of help by stimulating the community to discover and practise mental hygiene. Comprehensive efforts are also being made to obtain a complete picture of the nature and extent of the need for the treatment of chronic illness and disabling conditions and the rehabilitation of their victims.

\section{THE BOSE INSTITUTE, CALCUTTA}

\section{THIRTY-FIFTH ANNIVERSARY}

$\mathrm{T}$ HE director, Dr. R. C. Mazumdar, before presenting his report on the working of the Bose Institute for the past year, took the opportunity to refer to the fiftieth anniversary of the publication in 1902 of Sir Jagadish Chandra Bose's book "Response in the Living and the Non-living", which had at the time of its publication evoked a great deal of interest. He also announced the receipt of a legacy of $£ 5,000$ from the executors of the late Miss Edith Keating, of London. A fellowship is to be created in the Bose Institute, which will be known as the Edith and Richard Keating Research Fellowship.

Satisfactory progress has been made during the past year in the investigations carried out at the Mayapuri Research Station, Darjeeling, on plant virus and microbiological investigations. The different virus strains in seed potatoes, collected from the Seed Potato Farm at Rungbull, have been isolated and identified. Attempts are being made to produce hybrid strains, which will be immune to many of the virus infections, by crossing local commercial strains of potato with different wild South American species. The work planned is a long-range one and cannot bo successful without the financial aid and co-operation of the State Department of Agriculture, West Bengal. A scheme for continuation of this work has been submitted to the Government. At Mayapuri other applied investigations of importance to the Darjeeling District, like the introduction of white and red clover from seeds imported from Britain, are being taken up.

The Institute has been selected by the Indian Council for Agricultural Research for carrying out a five-year scheme of investigation on chemical eradication of weeds which infest fields growing rice and other economic crops.

Some aspects of photosynthesis, on which the nutrition of plants and animals are ultimately based, have been studied in the Institute for some time. At present, radioactive carbon imported from Harwell is being employed in the Institute to elucidate as tracer certain problems of assimilation of carbon during photosynthesis.

Successful X-ray irradiation of seeds of economic plants like jute, cotton and oil seeds with the view of evolving new economic types of mutants are being continued. With jute, a tall mutant has been stabilized; chemical examination of the fibre constituents, tensile strength and anatomical studies of the fibres have been started, as well as a method of impregnating with artificial resins bleached jute fibre, for increasing its wet tensile strength.

Nitrogen fixation by soil and nodule bacteria is being studied. Mention was also made in the report of various plant physiological investigations, including cultures of plant tissue in artificial media, and the study of the conditions for producing neoplastic growth in plant cells, similar to the development of cancer cells in animal tissues. The effect of antibiotic substances on plant nuclei is being studied.

The director also reported on the different schemes for providingadditional building accommodation for library and workshop, and for the acquisition of a large plot of good agricultural land to the north of Calcutta where the whole agricultural experimental work of the Institute can be centralized. At present considerable difficulty is being met with in maintaining the agricultural experiment stations of the Institute at two different places, one seventeen miles north of Calcutta at Bamangachi, and the other thirty-two miles south of Calcutta at Falta.

Dr. Mazumdar then delivered the fourteenth Acharya Jagadish Chandra Bose Memorial Lecture entitled "Growth of Scientific Spirit in Ancient India".

\section{RESEARCH IN THE SOCIAL SCIENCES}

$\mathrm{T}$

HE latest issue of that valuable publication, the "Register of Research in the Social Sciences"*, makes it possible to examine the trends of development that have become apparent in social research in recent years. The most important factor underlying these trends is, of course, the 'Clapham' grant given to the universities to make expansions possible in teaching and research in a number of the social sciences, and the effects are evident in the current issue of the "Register". In addition, the Government has taken action in a number of ways to expand social research, notably by direct grants to such bodies as the National Foundation for Educational Research, the British Institute of Management, and the Colonial Social Science Research Council. The provision made in this way has also been supplemented by generous benefactions from private agencies, the most important of which is the Nuffield Foundation.

The immediate impression which a quick survey of the "Register" makes on the mind is that social research is steadily expanding, that advances are, however, in a number of more-or-less disconnected areas rather than along a general line; and that, though an increasing amount of work of fundamental

* Register of Research in the Social Sciences in Progress and in Plan: No. 9, 1951-52, with a Directory of Research Institutions. Prepared at the National Institute of Economic and Social Research. Fdited by Feodora Stone. Pp. 188. (London : Cambridge University Press, 1952.) 158 . 
importance is being undertaken, much 'research' is still very superficial, directed too often to mere trivialities, or to objectives which only possess a temporary importance in an administrative context. The truth is, perhaps, that the social sciences are still unable to ask the really important questions with sufficient clarity and simplicity to make it possible to devise effective methods of answoring them. 'The economists have had most success in this endeavour, and this is perhaps why roughly a quarter of the whole of the research work summarized in the "Register" is in the field of economic analysis of one kind or another.

Development appears to be slowest in the exceedingly important area of social behaviour. The need for relating the study of psychology to that of social organization is obviously great, for this is one of the central problems of the social sciences; yet the whole psychology section devoted to "Gencral Social Problems" only runs to three pages, or about the same length as that of the agricultural economics section. Modern psychiatry only appears in the outlines of researches on rare occasions, as, for example, in those of the Medical Research Council, the T'avistock Institute of Human Relations, and the Institute for the Study and Treatment of Delinquency. 'The various university research organizations appear for the most part to have been deterred from entering the more adventurous fields of research, and to have been led to attach too high a value to the safe and respectable. Nevertheless, the wastage-rate among Ph.D. students in the social sciences still remains notoriously high. It is probable that the phase of 'settling-down' in social science research will have to go on for some time yet, and that bolder experiments will have to be encouraged, before substantial advances can be made otherwise than on one or two rather narrow fronts.

\section{RHODOPSIN AND INDICATOR YELLOW}

\section{By DR. F. D. COLLINS}

\section{Department of Biochemistry, University of Liverpool*}

$\mathrm{M}^{2}$ YCH is now known ${ }^{1,2}$ concorning the biochemistry of scotopic vision; but the chemical nature of the chromophore of rhodopsin (visual purple) is still obscure. When rhodopsin is exposed to light, various changes can be detected. Wald ${ }^{3}$ showed that a substance, which he called rotinene, could be extracted from rotinæ exposed to light, or treated with a polar solvent such as chloroform. Retinene had an absorption maximum at $385 \mathrm{~m} \mu$ in. chloroform, and at $664 \mathrm{~m} \mu$ in the presence of antimony trichloride dissolved in chloroform. Work in this laboratory ${ }^{4,5}$ showed that vitamin $A$ aldehyde was spectroscopically indistinguishable from retinene. This conclusion has been fully confirmed by sub. sequent investigations ${ }^{2,6}$. This research on retinene demonstrated that the most promising and practicable method of elucidating the chemical nature of rhodopsin and its breakdown products was by comparing their absorption spectra with those of materials prepared in the laboratory. The naturally occurring pigments are present in very small quantities (for example, $3 \mu \mathrm{gm}$. of chromophore per ox retina) and

* At present at the Department of Biochemistry, Australian National Unlversity, Canberra. all are unstable. However, the fact that rhodopsin is known to give vitamin $\mathbf{A}$ aldehyde provides a starting-point for the preparation of compounds for spectroseopic comparison with the naturally occurring pigments.

The position of indicator yellow in the visual cycle has been uncertain ever since it was first described by Lythgoe ${ }^{7}$. He found that a rhodopsin solution after irradiation formed a substance which exhibited variations in spectral absorption with changing $p H$. In alkaline aqueous digitonin the absorption maximum was at $365 \mathrm{~m} u$ while in acid it was changed to $440 \mathrm{~m} \mu$. Work in this laboratory ${ }^{8-10}$ showed that vitamin $\mathbf{A}$ aldehyde would combine, in alkaline solutions only, with aliphatic amines (in excess) to form a substance with an absorption maximum at $365 \mathrm{~m} \mu$ (solvent, aqueous ethanol). On the addition of one drop of concentrated hydrochloric acid, the maximum shifted to $440 \mathrm{~m} \mu$. It was thus clear that indicator yellow must be a compound of retinene and a free aminogroup, perhaps attached to a protein.

Two alternative conclusions are possible. (1) Retinene (in this case the first stable product of the bleaching of rhodopsin) would combine with any free amino-groups (for example, amino-acids or proteins) which might be present. "In this case indicator yellow would be a fortuitous artefact having no direct relevance to visual chemistry"'. Although retinone will only combine with amino-groups at an alkaline $p \mathrm{H}$, indicator yellow is none the less formed in irradiated rhodopsin solutions buffered at an acid $p \mathrm{H}^{10}$. This objection can be met by assuming that retinene, when first formed as a result of the irradiation of rhodopsin, is in an 'activated' form and that this 'activated' form combines rapidly with any free amino-groups. (2) The alternative conclusion is that the carbon-to-nitrogen bond present in indicator yellow is also present in rhodopsin.

On the basis of the first proposition, it might be expected that formation of indicator yellow would be totally prevented by 'blocking' the free aminogroups. A well-established means of doing this is by the use of formaldehyde ${ }^{11-13}$, as exemplified by the formol titration of amino-acids and proteins. A number of experiments have been carried out to test the validity of the above line of thought.

From the work of Levy ${ }^{1,12}$ and his co-workers tho reaction between an amino-acid and formaldehyde can be formulated as follows :

$$
\begin{aligned}
& R-\stackrel{+}{\mathrm{NH}_{3}} \rightleftharpoons R-\mathrm{NH}_{2}+\mathrm{H}^{+} \\
& R-\mathrm{NH}_{2}+\mathrm{HCHO} \rightleftharpoons R-\mathrm{NH}-\mathrm{CH} \mathrm{CH}_{2} \mathrm{OH} \\
& R-. \mathrm{NH}-\mathrm{CH}_{2} \mathrm{OH}+\mathrm{HCHO} \rightleftharpoons R-\mathrm{N}\left(\mathrm{CH}_{2} \mathrm{OH}\right)_{2}
\end{aligned}
$$

From the data11,12 it is possible to calculate the proportion of these forms which will be present in a given set of conditions (see table). The amount of freo amino-nitrogen in a rhodopsin solution is small, and an upper limit was established as follows. Two solutions (each $1 \mathrm{ml}$.) of rhodopsin $\left(13 \times 10^{-6} M\right.$ in respect to retinene) gave readings in a manometric Van Slyke apparatus which did not differ from the blank reading by more than $1.7 \mathrm{~mm}$. of mercury, a difference which corresponds to $3 \mu \mathrm{gm}$. aminonitrogen per ml. : to be quite certain, an upper limit of 5 ugm. amino-nitrogen per ml. was assumed, which is equivalent to $360 \times 10^{-6} M$. Assuming that the amino-groups are all present in the form of tyrosine (the amino-acid with the least affinity for formaldehyde) and that the 'activated' retinene reacts equally woll with the two forms of the free amino-group 